\title{
Pseudoneoplastic mimics in an inactive bladder associated with ureteral strictures
}

\author{
Erich K Lang, Matthew Smith, Quan Nguyen
}

SUNY, Downstate Medical School, Brooklyn, NY, USA

This 54 year old, malnourished white male was seen to determine management of an inactive bladder and ureteric strictures of the remaining right renal moiety.

Following several lithotripsy and lithotomy procedures, which failed to control renal calculi, the left kidney was removed surgically 7 years ago. After several ESWOL and 2 percutaneous nephrolithotripsies, the patient developed a uretero-pelvic junction obstruction, which was corrected by dismembered pyeloplasty. A known stricture in the distal right ureter was not corrected at this time. Rather it was elected to place a percutaneous nephrostomy to protect renal function.

The patient was then lost to follow-up for 4 years. His percutaneous nephrostomy functioned satisfactorily, despite the fact that it never been exchanged or replaced.

Figure 1 - The collecting system of the right kidney is within normal limits. Parenchymal thickness is maintained. A tight stricture is shown in the distal ureter (arrow).

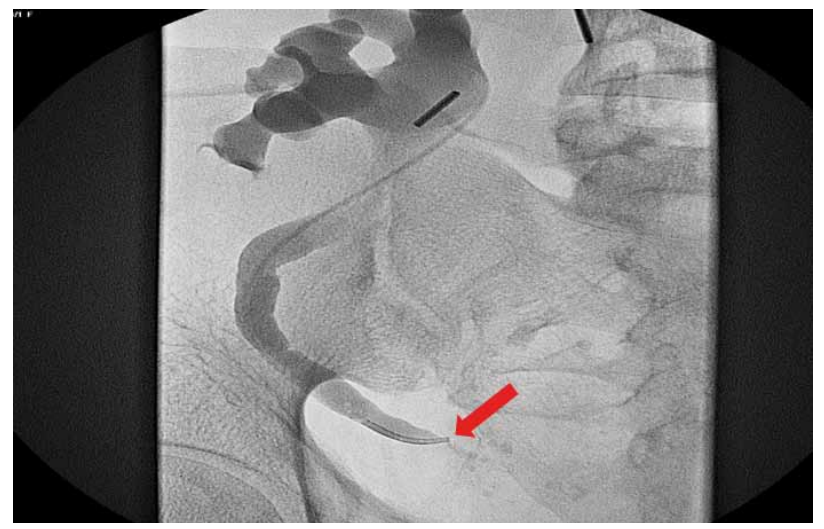

At the time of this admission, his creatinine was 1.9; BUN 32, K 4.8, RBC 4.5 mil, WBC 6800, HCT 38, HB 13.8. Urine from the nephrostomy was clear, 1-2 RBC / hpf, culture was negative.

An antegrade pyelogram revealed an essentially normal collecting system, but a severe stricture in the distal ureter. Under fluoroscopic guidance a $0.0147 \mathrm{~cm}$ platinum flexible-tip guide wire was passed across the stricture, followed by a 3 French catheter. Further injections demonstrated a $4 \mathrm{~cm}$ tight stricture, followed by another 0.5 $\mathrm{cm}$ tight napkin ring stricture (Figure-1). An exchange to a super-stiff Amplatz wire (0.038) was carried out and the strictures satisfactorily dilated with a $4 \mathrm{~cm}, 4$ \& $5 \mathrm{~mm}$ balloon (Figures 2 and 3).

A cystogram revealed innumerable defects in the bladder, reminiscent in appearance of malakoplakia, and distensible to only $120 \mathrm{~mL}$ (Figure-4).

Figure 2 - Over an 0.038 Amplatz wire a $4 \mathrm{~cm}, 4 \mathrm{~mm}$ balloon catheter has been advanced across a tight $4 \mathrm{~cm}$ stricture (arrow). A second napkin ring stricture is present distally.

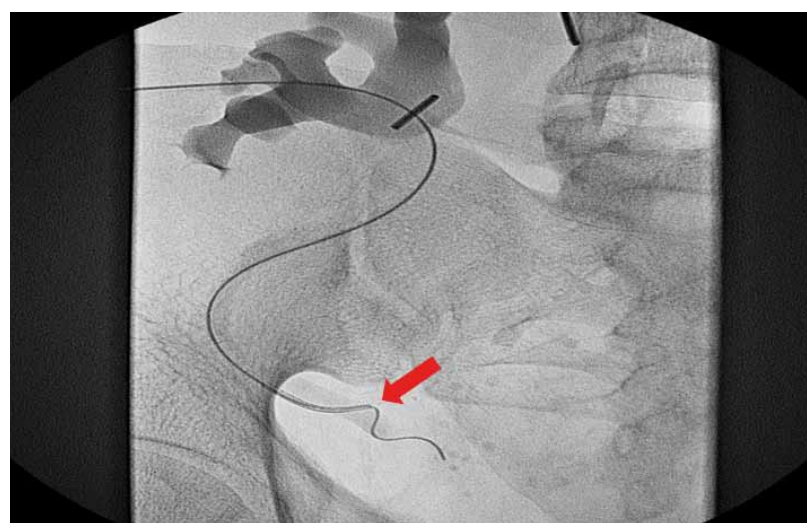


A washing of the bladder revealed debris, keratotic cells, but no evidence of malignancy, i.e. squamous metaplasia.

Despite the risk of squamous metaplasia in a bladder with malakoplakia, it was elected, to continue hydrodilation of the bladder to attain a normal volume while insuring drainage from the kidney via a double "J" stent $(1,2)$. The option of

Figure 3 - Over an 0.038 Amplatz wire a $4 \mathrm{~cm}, 5 \mathrm{~mm}$ balloon catheter has been advanced across a second napkin ring stricture (arrow).

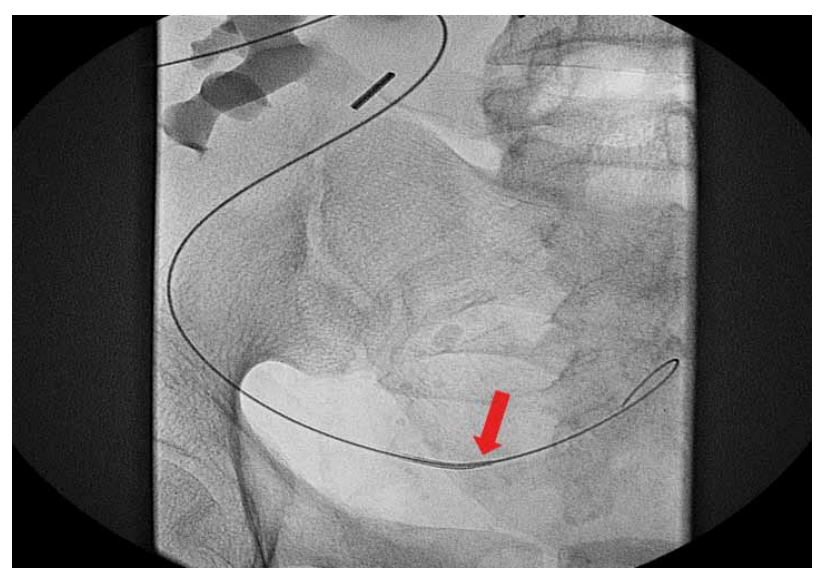

\section{REFERENCES}

1. Hameed 0, Humphrey PA: Pseudoneoplastic mimics of prostate and bladder carcinomas. Arch Pathol Lab Med. 2010; 134: 427-43.

\section{ARTICLE INFO}

Int Braz J Urol. 2013; 39: 286-7

Submitted for publication: December 21, 2011

Accepted after revision:

May 04, 2012 cystectomy and replacement by ileal loop neo-bladder was dismissed because of the patient's history of ureteric strictures.

On 2 year follow-up the bladder had successfully increased volume to $550 \mathrm{ml}$, mucosal surfaces were normal in appearance, and the right ureter showed no evidence of restricturing after the "J" stent had been removed some 18 months earlier.

Figure 4 - A cystogram demonstrates a contracted bladder with innumerable defects. These are reminiscent of changes attributable to malakoplakia in this inactive bladder (arrows).

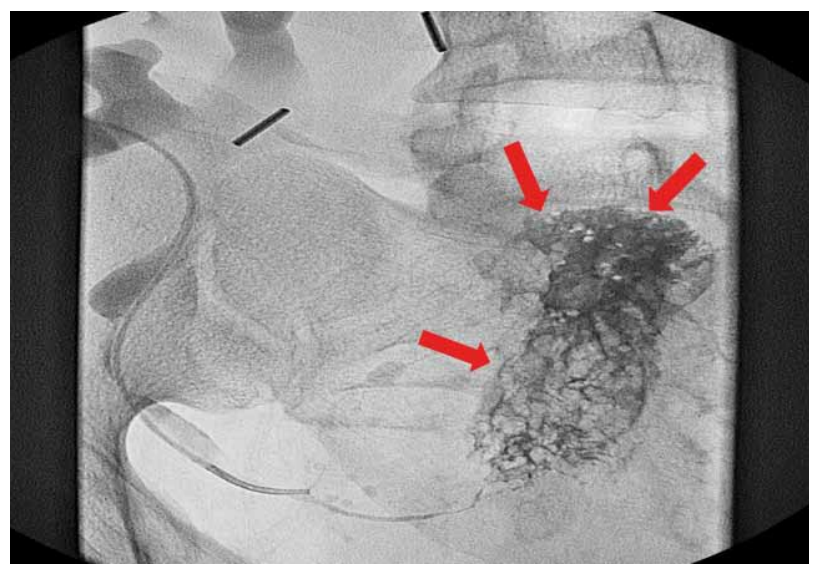

2. Senkul T, Yildirim S, Iseri C, Karademir K, Erden D, Baykal K: Histopathologic changes in the mucosa of ileal orthotopic neobladder--findings in 24 patients followed up for 5 years. Scand J Urol Nephrol. 2003; 37: 202-4. 